\title{
If you know something, say something: young children's problem with false beliefs
}

\author{
Mikkel B. Hansen ${ }^{1,2 *}$ \\ Department of Psychology and Educational Studies, Roskilde University, Roskilde, Denmark \\ 2 Department of Psychology, Université Paris 8, Paris, France
}

Edited by:

Daniel Richardson, University College London, UK

\section{Reviewed by:}

Henrike Moll, Max Planck Institute for Evolutionary Anthropology, Germany Atsushi Senju, Birkbeck College, UK

\section{*Correspondence.}

Mikkel B. Hansen, Department of Psychology and Educational Studies, P. O. Box 260, Roskilde University, DK-4000 Roskilde, Denmark.

e-mail:mikkelh@ruc.dk

\begin{abstract}
Whether young children understand that others may hold false beliefs is a hotly debated topic in psychology and neuroscience. Much evidence suggests that children do not pass this milestone in their understanding of other people until the age of 5 years. Other evidence suggests that they understand already in their second year. This study proposes a novel account of the logic of conversations about certain mental states. By modifying the discourse accordingly, children passed three false belief tasks at 3 years of age while they failed standard false belief tasks. The results support the view that even young children construe other people in adult-like psychological terms.
\end{abstract}

Keywords: theory-of-mind, pragmatics, language development, social cognition

\section{INTRODUCTION}

Children's understanding that people may hold and act on false beliefs, such as looking for the keys in the wrong place, is a milestone in their development towards an adult-like theory-of-mind. To attribute a false belief to someone, children must understand that there can be representations of the world that differ from their own accurate understanding (Dennett, 1978). Thus, false belief tasks are benchmarks of children's acquisition of a representational theory-of-mind, without which they are left unable to understand mistaken expectations, misguided actions, or misleading appearances.

On a typical false belief task, children are asked to predict where a puppet, Jill, thinks her chocolate is. The chocolate has been surreptitiously moved from where Jill originally put it, creating a false belief. A typical question could be, "Where does Jill think the chocolate is?" The correct answer is that Jill thinks the chocolate is in the original location. Yet children below $4 \frac{1}{2}$ years typically answer that Jill thinks that the chocolate is in the new and actual location (Wimmer and Perner, 1983).

Children's failure is striking because children actually remember the crucial pieces of information, i.e., they know where Jill put the chocolate and that she did not see it being moved. Even more striking is that children as young as 15 months reveal a tacit understanding of false belief on new nonverbal tasks (Clements and Perner, 1994; Garnham and Ruffman, 2001; Onishi and Baillargeon, 2005).

Nevertheless, overwhelming confirmation of the original results in hundreds of false belief studies across many cultures and languages has generally led to the conclusion that children do not develop the cognitive foundation required to understand mental representation until their fifth year (Perner, 1991; Gopnik and Wellman, 1994; Wellman et al., 2001).

I propose an alternative account based on the conversational logic involved in talking about certain mental states. In certain contexts, two speakers may not have direct knowledge about the identity or the location of an object. Instead, indirect knowledge may provide the best information. With regard to object identity, this could be appearance, e.g., "What is this?" "-It looks like an apple" (Austin, 1962). With regard to location, it could be where a third, absent, person thinks the object is, e.g., "Where is the chocolate?" "-Jill thinks it is in the refrigerator" (Willet, 1988).

It follows that the question, "Where does Jill think the chocolate is?" could be interpreted as a request for indirect knowledge about the actual location of the chocolate in certain contexts, rather than always being a unique request for Jill's belief. If children make this interpretation on false belief tasks, everyday conversational logic directs them to respond with the true location rather than with Jill's false belief. They will then fail the tasks irrespective of their understanding of false belief.

Consider a starker example. A firefighter arrives on the scene of a smoking building and asks an office worker, "Where does your manager think the fire is?" This is a plausible way to obtain indirect knowledge about the location of a fire. Crucially, answering such a request is an unremarkable event when neither the first person (the firefighter) nor the second person (the worker) knows the location of the fire. But when the second person knows better than the absent, third person (the manager), everyday conversational logic complicates the answer. Suppose the worker knows that the fire is in fact in the basement, even though his manager believes that it is in the kitchen. Though a literally correct answer, it would be uncooperative and even misleading of the worker to answer, "My manager thinks the fire is in the kitchen."

Suppose the firefighter instead arrived on the scene and asked, "Where will your manager look for the fire?" This is another plausible way to request the likely true location of the fire, if the firefighter also here assumes that the office worker does not know from personal experience. The worker could give the literal answer, "In the kitchen." But if he knows that the fire is in the basement, he would have sent the firefighter to the wrong place. Because people's actions reflect their thoughts, an action question can function pragmatically as a belief question. 
While the context in the firefighter example is clearly different from that of a false belief task, the point is to illustrate that situations exist where the question, "Where does X think Y is," is not meant to include, or is interpreted as including, somebody's false belief. Rather, it requests likely reality. For a variety of reasons, young children may not be sufficiently sensitive to the context to invoke precisely the meaning that is the premise of the false belief task. Thus, the current study experimentally manipulates the conversational context so that it is less equivocal to young children.

Requests for indirect knowledge are common and diverse. People must often solicit absent people's knowledge to learn about the world on the assumption that none of the present speakers knows the truth from personal experience, e.g. "What would Piaget say?" They are also likely to be familiar to children, e.g., "Please go ask your Mom where the keys are," or, "Does your Mom know where the keys are?" The same conversational logic applies here. To illustrate, a child would not reply that his mother said that the keys are in the kitchen if the child knows that they are in the basement. Or to the latter question solely give the literal answer, "No," if the child knows better than his mother. Such answers would be considered uncooperative, jocular, or a sign of undeveloped pragmatic understanding.

A request for indirect knowledge may simultaneously constitute an indirect request. A classic example of an indirect request is asking someone if she can pass the salt. The point is normally not to inquire about the respondent's physical ability, but to actually request the salt (e.g., Searle, 1975). In a similar vein, the child in the preceding two examples is not directly requested to report his mother's belief about the location of the keys, but most listeners would nevertheless interpret the questions in this way. However, the focus of this paper is not on indirect requests in Searle's sense but on the conversational logic of requests for indirect knowledge, such as asking about appearances as a path to the identity of an object or requesting someone's belief about the location of an object as a path to its actual location.

The analysis rests on two interrelated insights into language use from the field of psycholinguistics. First, interpreting a belief question as a request for indirect knowledge requires the assumption that the questioner lacks knowledge. Any conversational context partly consists of a set of assumptions about the other speakers' state of knowledge, termed the common ground (Stalnaker, 1978). At any point in a conversation, the common ground may determine the interpretation of new statements. Lack of knowledge about a location may be indicated explicitly, e.g., verbally with questions such as, "Where are the keys," or nonverbally by searching. It may also be assumed implicitly by the listener (Clark et al., 1983). I will consider it the ordinary context because it depends on the least number of conditionals.

In contrast, consider a context with two people staring at some keys. Here it would be redundant to interpret the question, "Where does Jill think the keys are?" as a request for indirect knowledge because the location is already known. I will call this the conditional context because it depends on shared knowledge.

Second, certain answers will be deemed uncooperative if they do not fulfill the intended meaning with the request. This is captured by Grice's account of everyday conversational logic (Grice, 1975). People make inferences, termed conversational implicatures, about a speaker's meaning based on the assumption that speakers adhere to four maxims that prescribe how to communicate most efficiently and rationally. The maxims belong to a general cooperative principle, under which people recognize a common purpose of a conversation and match answers to requests.

Reporting beliefs as indirect knowledge is mainly regulated by the Maxim of Quantity: Make a contribution no more or no less informative than required. In the exchange, "Son, where are the keys?" "-Well, Mom thinks they are in the cabinet," the son's seemingly irrelevant answer is nevertheless intelligible because people may infer that he cooperates with the request, but even at his most informative can only provide indirect knowledge about the location.

The maxim also constrains the son's answer. Suppose he knows that the keys are on the table but that his mother falsely thinks they are in the cabinet. He would be literally correct in saying, "Mom thinks the keys are in the cabinet." But this information would be superfluous and therefore uncooperative. People's false beliefs are uninformative when the common purpose of the conversation is to discover the true location.

The analysis applies to false belief tasks. Suppose young children presume the ordinary context of lack of knowledge about reality on the part of the experimenter, in the sense of, "(I'm looking for the chocolate and I assume you don't know from personal experience.) Where does Jill think the chocolate is?" The question then implies that the experimenter seeks indirect information about the likely location third-hand, through Jill's belief. But the point of the false belief task is that children know better than Jill. So if they wish to cooperate with the presumed request for the likely location and avoid violating the maxim of quantity, children must skip the uninformative step of Jill's false belief and respond with reality. Conversational logic compels children to say the truth if they know it, and leads them to fail the tasks.

To pass false belief tasks, then, children must presume the conditional context. In this context, it would violate the maxim of quantity to interpret the test question as a request for indirect knowledge about the likely location because both experimenter and child already know it.

It can be argued that children should already be aware of the conditional context. After all, the child and the experimenter jointly witnessed that the object was transferred to a new location. However, children may interpret the test question locally and invoke the ordinary context for several reasons.

First, the pragmatic implication of asking an honest question is lack of knowledge on the part of the experimenter, which for young children may override any shared knowledge and indicate the ordinary context. According to a related view (e.g., Siegal and Peterson, 1994), young children have yet to fully understand the conversational requirements of "academic" questioning where the questioner already knows the answer. The current discourse-based account explicates the conversational logic of certain mental-state expressions which is a novel extension of this more general view.

Second, the shell game-like atmosphere of the false belief task, in particular the location task, may suggest to young children that the context remains one of following the ball. A major challenge 
for researchers, then, is to design false belief tasks that block the possibility of presuming the local, ordinary context by clearly linking the test question to the preceding discourse.

Some related accounts that integrate the concept of common ground and the Gricean maxims to explain certain mental-state verbs can be found in the linguistic and philosophical literature. They are based on an original proposition by Kiparsky and Kiparsky (1970). These authors proposed categorizing cognitive verbs which take that complements into two broad categories. Factives are verbs where the complement can be presupposed to be true, e.g., know and forget, as in "John knows that it is raining." Non-factives are verbs where there is no presupposition as to whether the complement is true or not, e.g., think, believe, and say, as in, "John thinks that it is raining."

Kempson (1975) pointed out that for factive verbs the implication of truth of the complement does not necessarily hold. Her analysis of factivity based on the Gricean maxims and the concept of common ground showed that the implication of truth of the complement is context-dependent rather than a semantic property of the sentence in question. Conversely, in the case of non-factive verbs, Karttunen (1973) points out that non-factives such as say can in fact function as factives under certain conditions.

While these proposals support the context-dependent aspects of the discourse-based account in a general manner, it is important to note that to date, the fields of linguistics and philosophy are grappling with the issue of factivity. Numerous authors have identified flaws in the original semantic and logical explanations of the Kiparskys' proposal and have criticized the accuracy and scope of the distinction itself (for an overview, see Hazlett, 2010). Some authors instead favor a Gricean account like that of Kempson (e.g., Karttunen, 1998; Stalnaker, 1998; Hazlett, 2010). However, the versions of the factivity theory that include a Gricean analysis are presently too narrow to account for our phenomenon of interest. To properly cover children's understanding of the test questions on a variety of theory-of-mind tasks, such an account must not only include mental-state verbs that take that complements, but all types of expressions used on false belief tasks and appearance-reality tasks such as thinks, says, looks for, and looks like.

From a developmental point of view, Abbeduto and Rosenberg (1985) conducted the most extensive study based on the Kiparskys' proposal. They showed that before the age of 4 years, children treat non-factives as factives. The results confirm that the interpretation of thinks and believes may be difficult for 3-year-olds under circumstances other than the false belief task, but the study is nevertheless of limited relevance to the current account. The authors acknowledged the pragmatic weaknesses of the Kiparskys' original analysis but opted for ignoring them, thus not allowing a comparison with the broader view of the conversational context that is presented here.

The discourse-based account receives empirical support from its application to another major theory-of-mind task: the appearancereality task. On this task children are introduced to a deceptive object, such as a sponge that looks like a rock. At test, children below $4 \frac{1}{2}$ years of age typically fail, strikingly saying that the object not only is a sponge but also looks like a sponge. This suggests that they cannot distinguish appearances from reality (Flavell et al., 1986).
Similarly to the false belief task, the key test question, "What does this look like?" may be interpreted as a request for indirect knowledge about object identity in an ordinary context, e.g., "What is this?" "-Well, what does it look like?" (Austin, 1962). As the answer to the last question will provide indirect knowledge about the identity, it is subject to the conversational logic outlined above. For deceptive objects, answering with appearance would be superfluous because appearance is not a clue to their identity. It would violate the maxim of quantity.

To pass appearance-reality tasks, children must understand that the test question is embedded in the conditional context that both speakers already share knowledge of the identity of the object, which frees the child to answer with appearance. On three appearance-reality tasks that emphasized the conditional context, even 3 -year-old children gave nearly all-correct appearance responses while they failed the standard versions of the tasks (Hansen and Markman, 2005).

Young children should be similarly successful on false belief tasks that emphasize the conditional context. This would be strong evidence that children's problems with theory-of-mind tasks are due to difficulties with talking about mental states rather than with understanding the mind.

This hypothesis was tested on three major false belief tasks: (1) A location false belief task; (2) a contents false belief task; and (3) a representational change false belief task. On all tasks, the shared knowledge was emphasized in connection with the test question by simply restating it, e.g., "You and I know that the chocolate is in the basket, where does Jill think it is?" Compared to standard versions of each task, young children should do better in the emphasized context condition and thus demonstrate their knowledge of false belief.

\section{MATERIALS AND METHODS PARTICIPANTS}

Participants were 73 preschoolers from Sydney, Australia (mean: 3 years and 11 months, range: 3 years and 5 months to 4 years and 7 months). There were 34 boys and 39 girls, all English-speaking and primarily of Caucasian, middle socio-economic background. All participated in two conditions, except 11 children who only participated in one condition to complete the design.

The research was carried out in accordance with the ethical standards of the American Psychological Association for the treatment of research participants. Assent from the children was obtained prior to their participation. Sydney University's Human Research Ethics Committee approved the experiments.

\section{DESIGN AND MATERIALS}

There were three types of false belief tasks: location $(n=54)$, contents $(n=36)$, and representational change $(n=45)$. Each type of task had three conditions with equal numbers of participants in each: standard, emphasized context, and frame control. Each condition contained two similar scenarios acted out by the experimenter with various dolls and containers. Because of the relative similarity of tasks, conditions, and scenarios, children did not participate in all three types of tasks or all three types of conditions. Each child participated in two different types of tasks with an unrelated distractor task in between, and only in one of the conditions from 
each task, with the constraint the conditions were not the same. The combination of tasks and conditions was specified on six lists that were cycled through. This yielded a sufficiently counter-balanced pattern of the types of tasks, types of conditions, scenarios, and their respective orders. For example, a child might participate in a block of two similar scenarios of the standard condition of the location task, then receive a distractor task, and then participate in a block of two similar scenarios of the emphasized context condition of the contents task. Each child was seen individually in a quiet area of the preschool.

\section{PROCEDURE}

One scenario will be described for each task. Task 1 was a location false belief task. Elmo played with a ball in front of three cups. While holding the ball, he then turned all three cups upside-down and hid the ball in one of them, and then left the stage. Big Bird now surreptitiously moved the ball to another cup. The experimenter then explained that Elmo wanted to play with the ball again. Children in the standard condition were asked, "Where does Elmo think the ball is?" Children in the emphasized context condition were asked, "You and I know that the ball is in the <color of> cup, where does Elmo think it is?"

It is conceivable that the question frame itself invited children to use a low-level "opposites" strategy in the emphasized context condition such as, "You say one thing, so I say the other." This tendency might be enhanced by the fact that the two mental-state words think and know may be somewhat difficult to distinguish for children of 3 to 5 years of age (for a review, see Papafragou et al., 2007). Therefore, the location task included three locations, so even if children keyed off the location mentioned in the question, they could not use this information to select between the remaining two answers.

Additionally, a frame control condition was designed to control for this possibility. Children saw Elmo turn over the three cups while holding the ball, hide the ball in one cup, go outside and play, and return to find the ball. As Elmo returned, children were asked: "Elmo thinks the ball is in the yellow cup, where do you and I know it is?" As there was only a true belief, the correct answer was the same location as in the question, i.e., the yellow cup.

Because the phenomenon under investigation is contrastive, a control condition using exactly the same contrastive frame as the emphasized context condition but calling for a non-contrastive answer would be pragmatically infelicitous. Asking with a contrast where none can be found, for example in the case of a true belief setup, would not lead to a clear prediction for children's answers. Recall that on the discourse-based explanation, stating what somebody knows has implications for how to interpret the following think. However, the reverse should not be true so the solution was to simply reverse the order of these mental-state words in the test question of the frame control condition. If children were using an "opposites" strategy, blindly keying off the option mentioned in the test question in combination with uncertainty about the exact meaning of the mental-state words, they should tend to choose the incorrect answer options.

Task 2 was a contents false belief task (Hogrefe et al., 1986). Children were shown a band-aid box and asked, "What do you think is inside this box?" Most children answered band-aids. Children then opened the box and discovered that it contained crayons. The experimenter closed the box and introduced the character Dorothy, explaining that Dorothy had never looked inside the box before. Children in the standard condition were asked, "What does Dorothy think is inside the box?" Children typically fail answering "crayons" rather than "band-aids," seemingly unaware of Dorothy's false belief. Children in the emphasized context condition were asked, "You and I know that there are crayons inside, what does Dorothy think is inside the box?"

The frame control condition did not include false belief: Dorothy inspected the box with the lid open, so she could see the true contents. Children were then asked, "Dorothy thinks there are crayons in the box, what do you and I know is inside?" The correct answer was the same contents as mentioned in the test question, i.e., crayons. If children were guided by an "opposites" strategy, they should choose the other possible answer, i.e., band-aids.

Task 3 was a representational change false belief task (Gopnik and Astington, 1988). The task is based on the contents false belief task but rather than reporting someone else's false belief, this type of task requires children to report their own previous false belief. The introduction is the same as in the previous task, but after the experimenter closes the band-aid box, children in the standard condition are asked, "What did you think was in the box before you opened it?" Children typically fail by answering "crayons," seemingly unaware of their own previous false belief.

On a discourse-based account, a question about someone's past belief can be interpreted as a request for indirect knowledge. Consider the example of a judge asking a police officer, "We have to find the money. Where did you think it was?" If the police officer knows better than she previously did, it would be uncooperative of her to just report her previous belief and withhold the truth.

To ensure that children did not misread the context as one of searching for indirect knowledge in the way of a past, but presumably still valid, belief, children in the emphasized context condition were therefore asked, "You and I know there are crayons inside, what did you think was in the box before you opened it?"

In the frame control condition, children initially saw the bandaid box with the lid open and were asked, "What do you think is inside the box?" All answered, "crayons." The box was closed, and children were asked, "Before you thought there were crayons inside the box, what do you and I know is inside?" Since the child had seen the actual contents, there was no false belief and the correct answer was the same contents as mentioned in the test question, i.e., crayons. But if children were guided by an "opposites" strategy, they should not say crayons.

\section{RESULTS}

Children's responses to the test questions in Task 1 to 3 were scored online by the experimenter as correct or incorrect. The analyses were done on the number of correct answers. Because there were two scenarios within each condition, the maximum number of correct answers in each condition is 2 . Table 1 presents the data. Preliminary analyses showed no effects of task, order, gender, or age (split at mean age). As predicted, children's performance improved significantly on all three tasks when the conversational context of the test question was made clear. 
Table 1 | Mean number of correct answers out of 2 to test questions in task 1 to 3.

\begin{tabular}{|c|c|c|c|c|c|c|}
\hline \multirow[b]{3}{*}{ Type of task } & \multicolumn{6}{|c|}{ Condition } \\
\hline & \multicolumn{2}{|c|}{ Standard } & \multicolumn{2}{|c|}{$\begin{array}{l}\text { Emphasized } \\
\text { context }\end{array}$} & \multicolumn{2}{|c|}{$\begin{array}{l}\text { Frame } \\
\text { control }\end{array}$} \\
\hline & Mean & SD & Mean & SD & Mean & SD \\
\hline 1. False location $(n=54)$ & 0.44 & 0.78 & 1.17 & 0.99 & 1.94 & 0.24 \\
\hline 2. False contents ( $n=36$ ) & 0.08 & 0.29 & 1.25 & 0.97 & 1.92 & 0.29 \\
\hline $\begin{array}{l}\text { 3. Representational } \\
\text { change }(n=45)\end{array}$ & 0.40 & 0.74 & 1.40 & 0.83 & 1.67 & 0.72 \\
\hline
\end{tabular}

On the location false belief task, children in the emphasized context condition gave 1.17 correct answers (59\%) compared to 0.44 correct answers $(22 \%)$ in the standard condition, $t(34)=2.43$, $p=0.02$. Even under the complex verbal circumstances in the emphasized context condition, children performed better than chance, set at $33 \%, t(17)=2.18, p=0.04$.

On the contents and representational change false belief tasks, children in the emphasized context condition gave $1.25(63 \%)$ and $1.40(70 \%)$ correct answers, respectively, compared to $0.08(4 \%)$ and $0.40(20 \%)$, respectively, in the standard condition. Both differences were significant at $t(22)=4.01, p=0.001$ and $t(28)=3.49$, $p=0.002$, respectively.

Children's performance in the emphasized context condition was better than chance, set at $50 \%$, on the representational change task, $t$-one-tailed $(14)=1.87, p=0.04$, but not on the contents false belief task. This may be due to the fact that children's performance in the standard conditions of these two tasks was already low. It was below chance, $t(14)=3.15, p=0.007$, and $t(11)=11.00, p=0.001$, respectively, which was not the case for the location false belief task. Additionally, correct performance in the standard condition of all three tasks was generally on the low side of the average proportion of correct answers in Wellman et al. (2001) meta-analysis of hundreds of false belief conditions. Children's performance nevertheless fell within the range of the results that were included in the meta-analysis. Overall, it is impressive that younger children performed better than the standard condition on all three tasks and above chance on two of the three tasks (location and representational change), given the minimal modifications to the inherently pragmatically infelicitous standard tasks.

Despite there being only two answer options on the contents and representational change tasks, children's performance is likely not attributable to a low-level "opposites" strategy. This is partly because children nearly aced the control condition at an average of 1.84 correct answers out of 2 across the three tasks, despite a question frame that might plausibly elicit an "opposites" answer. In planned contrasts, this differed significantly from the abovementioned chance levels for each task, $t(42)=24.92, p=0.001$. Thus, children are likely not guided by a conceivable tendency to automatically choose the opposite answer of the one mentioned in the test question. However, the frame control condition was not intended to stand alone but to be considered within the overall pattern of results. The quite similar location false belief task had not just two but three answer options, between which children still choose correctly. Furthermore, on all three tasks children gave an average of $36 \%$ incorrect answers in the enhanced context condition which they would be unlikely to do on an automatic opposites interpretation.

\section{DISCUSSION}

Standard false belief tasks may mislead young children because questions about other people's thoughts on reality (including their intended actions which reflect their thoughts) are a perfectly fine way to obtain indirect knowledge about reality in certain contexts such as the ordinary context, e.g., "I'm looking for the chocolate. Where does your Mom think it is?" Such questions require answering with the truth, not beliefs known to be false. If children assume the ordinary context on the false belief task, it places them in a pragmatic bind because they know the truth about the location better than the absent, third person. It would be awkward not to say the truth, so young children do, and fail the standard task.

Young children may assume the ordinary context, perhaps even by default, for a number of reasons. First and foremost, the test question expresses ignorance on the part of the experimenter if interpreted as an honest question, which young children have been argued to do on a number of standard developmental tasks (e.g., Siegal and Peterson, 1994). The perception of an honest question indicates the ordinary context rather than the conditional context. Second, the ordinary context of looking for knowledge about reality is supported by the follow-the-ball atmosphere of the test scenario, especially in the case of the location false belief task. Finally, the ordinary context depends on fewer inferences.

The analysis of the discourse of the false belief task suggested that interpreting the test question as it is meant requires complex pragmatic inferences. Crucially, children must consider how the state of mind of the experimenter is factored into the discourse. In order to understand the test question correctly, children must integrate into their interpretation that the experimenter already knows the location, here called the conditional context. He can therefore not intend to gain indirect knowledge about it from the child, because it would violate normal rules of conversation to ask about something he already knows.

To help young children achieve better integration of the discourse of the false belief task, the experimenter in the present study clearly stated that he was already aware of the location as part of the test question. With this slight modification to the discourse, 3-year-olds were able to pass three false belief tasks, while failing the standard versions. Because the intervention was minimal-no new information was added and the structure of the task was unchanged-these results are quite strong evidence that contrary to current theories (e.g., Perner, 1991; Gopnik and Wellman, 1994), at least older 3-year-olds have the cognitive foundation needed to understand beliefs, which is being masked by the standard false belief tasks because they rely on context-dependent mentalstate verbs.

In contrast, clearly non-reality-based mental-state verbs such as pretend, dream, and fantasize do not semantically lend themselves to interpretations as requests for indirect knowledge (see Morgan, 
1969; Kempson, 1975). Indeed, young children pass some false belief tasks couched in terms of pretense (Flavell et al., 1987; Woolley and Wellman, 1990). The discourse-based account then solves the puzzle of why even 1-year-olds seem to understand pretend play, which implicates some understanding of mental representation, and pass new nonverbal tests, while young children still fail standard false belief tasks.

A remaining challenge is to account for the developmental change that enables children above $4 \frac{1}{2}$ years to pass the standard false belief tasks. The results hint that the core problem for younger children may lie in understanding the pragmatics of how and when to connect current and preceding discourse, in particular factoring the common ground of shared knowledge into their interpretation of the test question. Older children may have achieved a better understanding that the experimenter's seemingly honest question does not negate his previous indication that he already knows the truth. In contrast, younger children may not realize that this shared information is sustained throughout a conversation and even trumps contradictory pragmatic indicators.

Two sources of evidence point to a related development between 3 and 5 years of age in children's ability to sustain preceding pragmatic information when interpreting ambiguous statements.

In one study, Avrutin and Coopmans (2000) investigated which inferences 3- to 5-year-old children made to bridge an ambiguous statement with preceding utterances. For example, children saw a picture of a boy with red pants and a girl with green pants. The boy was eating while the girl was playing. Children heard a puppet say, "There is a boy eating. The pants are green." Children's task was to judge whether the puppet's sentence was true or false. Five-year-olds would bridge the definite reference back to the boy and conclude that the sentence was false, whereas 3-year-olds identified the sentence as true or false at chance. In subsequent studies, the authors found that it took only a slight re-arrangement of the sentence to increase the performance of 3-year-olds. Making the topic of the initial phrase more salient by moving it to the beginning of the sentence, e.g., "A boy is eating. The pants are green," helped most children correctly identify the sentence as false in relation to the picture.

\section{REFERENCES}

Abbeduto, L., and Rosenberg, S. (1985). Children's knowledge of the presuppositions of know and other cognitive verbs. J. Child Lang. 12, 621-641.

Allen, R. (1991). Integration of communicational cues by very young children. J. Psycholinguist. Res. 20, 389-402.

Andrews, G., Halford, G. S., Bunch, K. M., Bowden, D., and Jones, T. (2003). Theory of mind and relational complexity. Child Dev. 74, 1476-1499.

Austin, J. L. (1962). Sense and Sensibilia. New York: Oxford University Press.

Avrutin, S., and Coopmans, P. (2000). "Children who build bridges," in Proceedings of the 24th Annual Boston University Conference on Language Development, eds S. C. Howell, S. A. Fish, and T. Keith-Lucas (Somerville, MA: Cascadilla Press), 80-91.
Bacharach, V.R., and Luszcz, M.A. (1979). Communicative competence in young children: the use of implicit linguistic information. Child Dev. 50, 260-263.

Carlson, S. M., and Moses, L. J. (2001). Individual differences in inhibitory control and children's theory of mind. Child Dev. 72, 1032-1053.

Clark, H. H., Schreuder, R., and Buttrick, S. (1983). Common ground and the understanding of demonstrative reference. J. verbal Learn. Verbal Behav. 22, 245-258.

Clements, W. A., and Perner, J. (1994). Implicit understanding of belief. Cogn. Dev. 9 377-395.

Dennett, D. C. (1978). Brainstorms: Philosophical Essays on Mind and Psychology. Montgomery, VT: Bradford Books.

Flavell, J. H., Flavell, E. R., and Green, F. L. (1987). Young children's knowledge

Another set of studies investigated whether children used the implicit pragmatic suggestions of the discourse setting to infer the topic of a conversation (Shatz, 1978; Bacharach and Luszcz, 1979; Allen, 1991). Here, 3- to 5-year-olds saw pictures that invited comments on an aspect of the picture. The ambiguous request was preceded by comments about either actions or objects. For example, Bacharach and Luszcz (1979), would preface a picture with, "Horses can run. Horses can jump fences. Horses can eat hay. Here's a picture, tell me about it." Or, "A cow is an animal. A rabbit is an animal. A cat is an animal. Here's a picture, tell me about it." Children's answers showed that 5-year-olds, but not 3-year-olds, matched the action setting with action answers and the information setting with information answers.

While the studies of bridging inferences and referential ambiguity are not direct analogues to the current account of the false belief task, the results give some reason to think that younger children may in fact struggle with making the required links to preceding discourse which older children more readily accomplish.

More basic cognitive achievements such as general information processing abilities may contribute to this pragmatic development. Increased processing capacity and an improved ability to inhibit knowledge about current information in favor of more distant information have previously been found to correlate with the standard false belief task (Frye et al., 1995; German and Leslie, 2000; Carlson and Moses, 2001; Andrews et al., 2003). While pragmatic inferences require understanding people's communicative intentions and thus can be described in theory-of-mind terms, the present results do not support the radical change in children's theory-of-mind at the late age of $4 \frac{1}{2}$ years proposed by current theories.

\section{ACKNOWLEDGMENTS}

This research was supported by a grant from the Danish Research Council. I thank the parents, teachers, and children in the Sydney area who participated in these studies. Thanks also to David Pasalich and Katrine Hemmingsen who helped collect and code data, and to Arne Poulsen, Britta Jensen, Ellen Markman, Marc de Rosnay, and the reviewers for helpful comments.

about the apparent-real and pretendreal distinctions. Dev. Psychol. 23, 816-822.

Flavell, J. H., Green, F. L., and Flavell, E. R. (1986). Development of knowledge about the appearance-reality distinction. Monogr. Soc. Res. Child Dev. 51.

Frye, D., Zelazo, P.D., and Palfai, T. (1995). Theory of mind and rule-based reasoning. Cogn. Dev. 10, 483-527.

Garnham, W. A., and Ruffman, T. (2001). Doesn't see, doesn't know: is anticipatory looking really related to understanding of belief? Dev. Sci. 4, 94-100.

German, T. P., and Leslie, A. M. (2000). "Attending to and learning about mental states," in Children's Reasoning and the Mind, eds P. Mitchell and K. Riggs (Hove: Psychology Press), 229-252.

Gopnik, A., and Astington, J. W. (1988). Children's understanding of represen- tational change and its relation to the understanding of false belief and the appearance-reality distinction. Child Dev. 59, 26-37.

Gopnik, A., and Wellman, H. M. (1994). "The 'theory' theory." in Mapping the Mind: Domain Specificity in Cognition and Culture, eds L. Hirschfeld and S. Gelman (New York: Cambridge University Press), 257-293.

Grice, H. P. (1975). "Logic and conversation (from the William James lectures, Harvard University, 1967)," in Syntax and Semantics 3: Speech Acts, eds P. Cole and J. Morgan (New York: Academic Press), 41-58.

Hansen, M. B., and Markman, E. M. (2005). Appearance questions can be misleading: a discourse-based account of the appearance reality problem. Cogn. Psychol. 50, 233-263. 
Hazlett,A. (2010). The myth of factive verbs. Philos. Phenomenol. Res. 80, 497-522.

Hogrefe, G.-J., and Wimmer, H., and Perner, J. (1986). Ignorance versus false belief: a developmental lag in attribution of epistemic states. Child Dev. 57, 567-582.

Karttunen, L. (1973). Presuppositions of compound sentences. Linguistic Inquiry, 4, 169-193.

Karttunen, L. (1998). "Presupposition and linguistic context," in Pragmatics: Critical Concepts, ed. A. Kasher (London: Routledge), 32-46.

Kempson, R. (1975). Presupposition and the Delimitation of Semantics. Cambridge, MA: Cambridge University Press.

Kiparsky, P., and Kiparsky, C. (1970). "Fact," in Progress in Linguistics eds M. Bierwisch and K. E. Heidolph (The Hague: Mouton and Co), 143-173.

Morgan, J. L. (1969). “On the treatment of presupposition in transformational grammar," in Papers from the Fifth Regional Meeting of the Chicago Linguistic Society, eds R. Binnick, A. Davidson, G. Green and J. Morgan.
(Chicago: University of Chicago), 167-177.

Onishi, K. H., and Baillargeon, R. (2005). Do 15-month-old infants understand false beliefs? Science 308, 255-258.

Papafragou, A., Cassidy, K., and Gleitman, L. (2007). When we think about thinking: the acquisition of belief verbs. Cognition 105, 125-165.

Perner, J. (1991). Understanding the Representational Mind. Cambridge, MA: MIT Press.

Searle, J. R. (1975). "Indirect speech acts," in Syntax and Semantics 3: Speech Acts, eds P. Cole and J. Morgan (New York: Academic Press), 59-82.

Shatz, M. (1978). On the development of communicative understandings: An early strategy for interpreting and responding to messages. Cogn. Psychol. 10, 271-301.

Siegal, M., and Peterson, C. (1994). "Children's theory of mind and the conversational territory of cognitive development," in Children's Early Understanding of Mind: Origins and
Development, eds C. Lewis and P. Mitchell (Hillsdale, NJ: Lawrence Erlbaum Associates), 427-456.

Stalnaker, R. (1978). “Assertion," in Syntax and Semantics. IX. Pragmatics, ed. P. Cole (New York: Academic Press), 315-322.

Stalnaker, R. (1998). "Pragmatic presuppositions," in Pragmatics: Critical Concepts, ed. A. Kasher (London: Routledge), 16-31.

Wellman, H. M., Cross, D., and Watson, J. (2001). Meta-analysis of theoryof-mind development: the truth about false belief. Child Dev. 72, 655-684.

Willet, T. L. (1988). A cross-linguistic survey of the grammaticalization of evidentiality. Stud. Lang. 12, 51-97.

Wimmer, H., and Perner, J. (1983). Beliefs about beliefs: Representation and constraining function of wrong beliefs in young children's understanding of deception. Cognition 13 , 103-128.

Woolley, J. D., and Wellman, H. M. (1990). Young children's understanding of realities, nonrealities, and appearances. Child Dev. 61, 946-961.

Conflict of Interest Statement: The author declares that the research was conducted in the absence of any commercial or financial relationships that could be construed as a potential conflict of interest.

Received: 19 April 2010; paper pending published: 07 May 2010; accepted: 04 June 2010; published online: 05 July 2010.

Citation: Hansen MB (2010) If you know something, say something: young children's problem with false beliefs. Front. Psychology 1:23. doi: 10.3389/fpsyg.2010.00023

This article was submitted to Frontiers in Developmental Psychology, a specialty of Frontiers in Psychology.

Copyright (C) 2010 Hansen. This is an open-access article subject to an exclusive license agreement between the authors and the Frontiers Research Foundation, which permits unrestricted use, distribution, and reproduction in any medium, provided the original authors and source are credited. 